\title{
The relationship between myocardial fibrosis and left ventricular mass regression following aortic valve replacement
}

\author{
Serik Aitaliyev ${ }^{1}$, Egle Rumbinaitè ${ }^{2}$, Rokas Nekrošius ${ }^{1}$, Vytenis Keturakis ${ }^{1}$, Rimantas Benetis $^{1}$
}

${ }^{1}$ Department of Cardiac, Thoracic and Vascular Surgery, Hospital of Lithuanian University of Health Sciences, Kauno Klinikos, Medical Academy, Lithuanian University of Health Sciences, Kaunas, Lithuania

${ }^{2}$ Department of Cardiology, Medical Academy, Lithuanian University of Health Sciences, Kaunas, Lithuania

Received: 2021-05-18.

Accepted: 2021-06-21

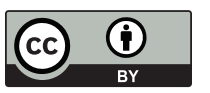

This work is licensed under a Creative Commons Attribution 4.0 International License

J Clin Med Kaz 2021; 18(4):39-45

Corresponding author:

Serik Aitaliyev.

E-mail: aitaliyev.serik@gmail.com; ORCID: 0000-0002-3014-9100

\section{Abstract}

Aim: Aortic valve diseases are associated with myocardial fibrosis. The relationship between severity of myocardial fibrosis and left ventricular mass reduction (LVMR) after aortic valve replacement (AVR) still needs to be elucidated.

Material and methods: In a single-center, retrospective trial, 130 patients underwent AVR with/without concomitant surgery. The study population was divided by etiology into aortic stenosis (AS) and aortic regurgitation (AR) groups. LV end-diastolic diameter, LV septal and posterior thicknesses, LV mass, and aortic annulus were obtained in all study patients. Left ventricular mass regression index (iLVMR) was found by the difference between preoperative iLVM and follow-up iLVM. iLVMR in months was calculated by divided iLVMR on the number of months before follow-up visit. Myocardial tissue was embedded in paraffin, and sectioned into $4 \mu \mathrm{m}$ slices for histological staining (picrosirius red) and scanning. The fraction of myocardial volume occupied by collagen tissue was determined.

Results: The left ventricular remodeling of AS and AR patients is presented in Table 3. There was significant LV mass reduction in both aortic valve disease groups in the follow-up period (AS group, $p<0.001$; AR group, $\mathrm{p}<0.05$ ). The number of LVH cases decreased in both groups in the follow-up period (AS group, $p<0.001$; AR group, $p<0.05$ ). In Post-AVR period the ejection fraction of LV did not improve in the AS group, compare to AR group $(p<0.05)$. In both groups number of patients with impaired LV EF was increased in Post-AVR period, but not significantly. Moreover, the LV septal thickness, and iLVEDD significantly decreased in the AS group $(p<0.001$ and $p<0.001)$, compared to the AR group ( $p=N S, p<0.05)$.

We did not found correlations between MF and LVM in preoperative, and follow-up periods for AS and AR groups. Moreover, MF did not correlate significantly to iLVMR and iLVMR in months. A significant correlation exists in AS patients between MF and preoperative iLVEDD ( $r=0.21, p=0.04)$.

Conclusion: The LVM reduction was observed in both AS and AR groups. LVM of AS group recovered more quickly than that of AR group. In our study MF does not affect LVM regression. Large cohort of patients with myocardial biopsies and long-term follow-up are needed to access the impact of the MF on the LVMR.

Key words: aortic valve, myocardial fibrosis, aortic valve replacement, left ventricular mass regression

\section{Introduction}

Aortic valve diseases, especially aortic stenosis, represent the most common pathology in the growing population. The gold standard of treatment in most cases remains an aortic valve replacement (AVR). However, modern implanted cardiac prosthesis valves still cannot outrival native cardiac valves. This leads to low left ventricle mass regression (LVMR), a worsened quality of life, and the maintenance of heart failure symptoms after AVR [1]. Moreover, poor LV remodeling leads to a high mortality [2]. 
Aortic valve diseases are associated with myocardial fibrosis (MF) [3]. Myocardial fibrosis is a result of a variety of quantitative and qualitative changes in the myocardium, leading to the development of cardiac dysfunction. It is mainly characterized by dysregulated collagen turnover and excessive diffuse collagen accumulation. Many of the supporting data derived from non-human cardiac tissues have dubious applicability to human myocardium. Moreover, recent data showed that diffuse fibrosis after AVR can regress [4] and predicts mortality [5] according to late gadolinium enhancement by cardiovascular magnetic resonance. On the other hand, MF failed to resolve 9 months post AVR [6] and did not influence on the mortality rate [7]. Aim of our study was to assess relationship between the myocardial fibrosis and the LV remodeling after AVR.

\section{Materials and methods}

In a single-center, retrospective trial, 130 patients underwent AVR with/without concomitant surgery. The study population was divided by etiology into aortic stenosis (AS) and aortic regurgitation (AR) groups. In the pre-AVR and post-AVR periods (6.77 \pm 2.05 months), 130 and 97 patients underwent echocardiography, respectively.

\section{Echocardiography}

The following LV measurements and aortic valve parameters were obtained in all patients: LV end-diastolic diameter, LV septal and posterior thicknesses, LV mass, and aortic annulus. The LV ejection fraction (EF) was determined using the Simpson biplane method. Low LVEF refers to EF < $45 \%$. Left ventricular function was assessed from the short axis of the parasternal view, and left ventricular hypertrophy (LVH) was defined by linear measurements as $95 \mathrm{~g} / \mathrm{m} 2$ in women and $115 \mathrm{~g} / \mathrm{m} 2$ in men [8]. Left ventricular mass regression index (iLVMR) was found by the difference between preoperative iLVM and follow-up iLVM. iLVMR in months was calculated by divided iLVMR on the number of months before follow-up visit.

All Doppler measurements were averaged during sinus rhythm for three cardiac cycles and for five cardiac cycles with rhythm disturbance. Doppler echocardiography during the Pre-AVR and Post-AVR visits was performed with a protocol developed for this study. Transthoracic imaging was performed by one of three highly trained sonographers using the Philips EPIQ 7G and Philips CX50. For each case, 2D images and colour-flow Doppler in multiple views were included.

\section{Histological analysis}

Myocardial tissue was procured from 130 stable patients undergoing elective AVR surgery, embedded in paraffin, and sectioned into $4 \mu \mathrm{m}$ slices for histological staining and scanning. Myocardial tissue was obtained from the basal part of the interventricular septum of patients undergoing AV replacement. For each case, formalin-fixed, $10 \%$ paraffin-embedded sections were produced for histological analysis. There were no procedure-related complications observed.

The fraction of myocardial volume occupied by collagen tissue was determined by quantitative morphometry with an automated image analysis system (motorized Olympus BX61 microscope, Evolution QEi camera and Media Cybernetics ImagePro AMS software) in sections stained with collagenspecific picrosirius red. The collagen volume fraction was assessed as divided the sum of the fibrotic areas of the section
Figure 1A and 1B. - Selected examples illustrating myocardial fibrosis

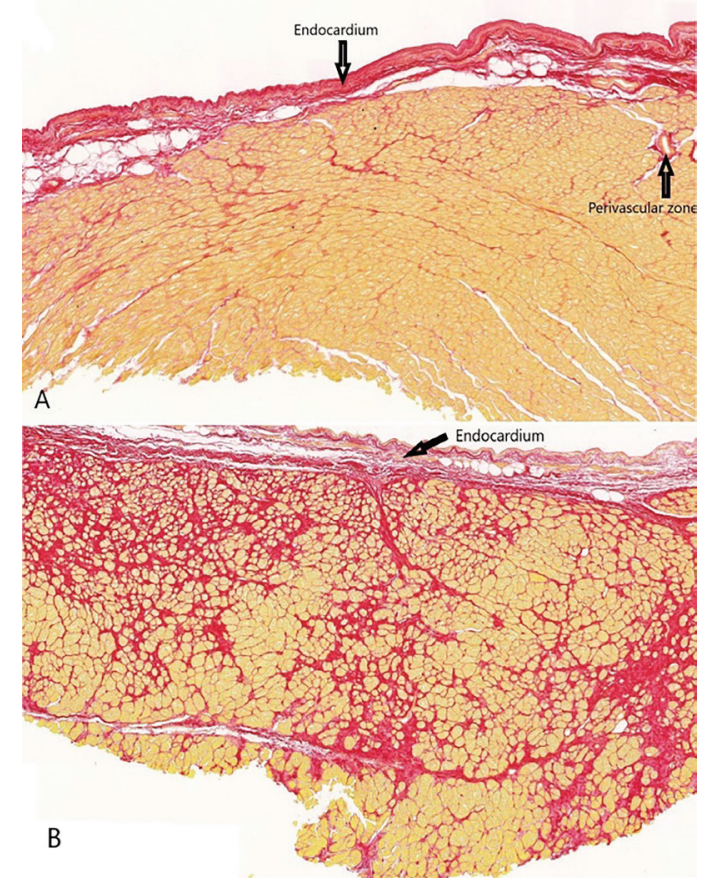

by that of the total tissue area expressed as a percentage [10]. The patients were classified according to the myocardial fibrosis severity on mild (MF is $<20 \%$ ), moderate (MF is $20 \%-30 \%$ ), severe (MF is $>30 \%$ ). Figure 1 illustrates histological specimens stained with picrosirius red showing $0.2 \%(\mathrm{~A})$ and $21.5 \%(\mathrm{~B})$ of interstitial MF (red color). The endocardium and perivascular area were excluded from the analysis.

All human sections were acquired from Kaunas clinics of Lithuanian University of Health Sciences. This research protocol, using stored samples without a link with patient identities, was approved by the Ethics Committee of the Lithuanian University of Health Sciences. Informed consent was obtained from all patients.

\section{Statistical analysis}

All normally distributed data are expressed as means \pm standard deviations or numbers (percentages). Continuous data with non-normal distributions are represented as the median (interquartile range). Differences between continuous variables were tested using Student's t-test or the Mann-Whitney test, depending on whether the data were normally distributed or not. Differences between categorical variables were evaluated using chi-squared or Fisher's exact tests. Relations between MF and LV parameters were analyzed through the Spearman correlation coefficient. Paired T-tests were used to examine the echocardiographic difference of preoperative and postoperative data. The difference was considered significant when the p-value was less than 0.05 . All statistical analyses were performed using the IBM SPSS Statistics for Windows version 27.0 (IBM Corp., Armonk, NY, USA).

\section{Results}

Preoperative data of AS and AR groups were not significantly different, except for the time from the first symptom (Table 1). Time before referring to surgery was shorter in the AR group than in the AS group $(\mathrm{p}<0.05)$. Preoperative mortality risk and comorbidities were not significantly different between AS and AR groups. 


\begin{tabular}{|c|c|c|c|}
\hline Variables & AS $(n=116)$ & $\operatorname{AR}(n=14)$ & P-Value \\
\hline Age (years) & $68.4 \pm 9.8$ & $65.4 \pm 10.1$ & NS \\
\hline Female sex & $48(41.4 \%)$ & $4(28.6 \%)$ & NS \\
\hline BSA (m2) & $1.9 \pm 0.3$ & $1.9 \pm 0.3$ & NS \\
\hline BMI (kg/m2) & $28.9 \pm 5.4$ & $27.6 \pm 4.1$ & NS \\
\hline \multicolumn{4}{|l|}{$\begin{array}{l}\text { Severity of aortic valve } \\
\text { pathology }\end{array}$} \\
\hline severe & $95(81.9 \%)$ & $9(64.3 \%)$ & NS \\
\hline moderate & $20(17.2 \%)$ & $5(35.7 \%)$ & NS \\
\hline mild & $1(0.9 \%)$ & No & NS \\
\hline \multicolumn{4}{|l|}{ NYHA class } \\
\hline IV & $1(0.7 \%)$ & $1(7.1 \%)$ & NS \\
\hline III & $59(50.9 \%)$ & $6(42.9 \%)$ & NS \\
\hline II & $55(47.4 \%)$ & $7(50.0 \%)$ & NS \\
\hline I & $1(0.7 \%)$ & No & NS \\
\hline $\begin{array}{l}\text { Onset of symptoms } \\
\text { (month) }\end{array}$ & $7.5(0-84)$ & $5.0(0-48)$ & 0.05 \\
\hline Smoker & $4(3.4 \%)$ & No & NS \\
\hline $\mathrm{AH}$ & $96(82.8 \%)$ & $13(92.9 \%)$ & NS \\
\hline Dyslipidemia & $69(59.5 \%)$ & $8(57.1 \%)$ & NS \\
\hline $\begin{array}{l}\text { Chronic obstructive } \\
\text { pulmonary disease }\end{array}$ & $10(8.6 \%)$ & $2(14.3 \%)$ & NS \\
\hline $\begin{array}{l}\text { Peripheral vessel } \\
\text { diseases }\end{array}$ & $20(17.2 \%)$ & $3(21.4 \%)$ & NS \\
\hline $\mathrm{DM}$ & 17 (14.7\%) & No & NS \\
\hline History of stroke & $6(5.2 \%)$ & $1(7.1 \%)$ & NS \\
\hline IHD & $73(56.2 \%)$ & $9(6.9 \%)$ & NS \\
\hline MI & $20(17.2 \%)$ & $3(21.4 \%)$ & NS \\
\hline Kidney, Liver disorders & $23(19.8 \%)$ & $5(35.7 \%)$ & NS \\
\hline BAV & $37(31.9 \%)$ & $4(28.6 \%)$ & NS \\
\hline Degenerative etiology & $112(96.6 \%)$ & $13(92.9 \%)$ & NS \\
\hline STS score (\%) & $2.2(0.4-23.5)$ & $2.7(0.5-11.7)$ & NS \\
\hline EuroSCORE II (\%) & $2.5(0.5-42.4)$ & $3.1(1.1-18.0)$ & NS \\
\hline
\end{tabular}

There were Pre-AVR echocardiography differences in the left ventricular end-diastolic dimension (LVEDD) $(\mathrm{p}<0.05)$, indexed left ventricular end-diastolic diameter (iLVEDD) $(p<0.05)$, and posterior wall thickness $(p<0.05)$ between AS and AR, but not in the Post-AVR period. LVEDD and iLVEDD were high in the AR group, whereas the posterior wall thickness was high in the AS group. Although EF were preoperatively similar, there was a difference between those in the follow-up groups $(\mathrm{p}<0.05)$. LVM and iLVM were similar between AS and AR groups in the Pre-AVR and PostAVR periods.

Preoperative and intraoperative data of AS and AR patients are summarized in Table 2. There were no statistical differences in intraoperative data between groups. Mild myocardial fibrosis was detected in the majority of AS and AR patients (93.1\% vs $85.7 \%$ ). However, the mean prosthesis size in the AR group was larger than that in the AS group of patients $(\mathrm{p}<0.05)$. Moreover, ICU stay of AR group was longer than those in AS group $(\mathrm{p}<0.05)$. Postoperative treatment was not statistically different between AS and AR groups.

The left ventricular remodeling of AS and AR patients is presented in Table 3. There was significant LV mass reduction in both aortic valve disease groups in the followup period (AS group, $\mathrm{p}<0.001$; AR group, $\mathrm{p}<0.05$ ). The number of LVH cases decreased in both groups in the followup period (AS group, $\mathrm{p}<0.001$; AR group, $\mathrm{p}<0.05$ ). In PostAVR period the ejection fraction of $\mathrm{LV}$ did not improve in the AS group, compare to AR group $(\mathrm{p}<0.05)$. In both groups number of patients with impaired LV EF was increased in Post-AVR period, but not significantly. Moreover, the LV septal thickness, and iLVEDD significantly decreased in the AS group $(\mathrm{p}<0.001$ and $\mathrm{p}<0.001)$, compared to the AR group $(\mathrm{p}=\mathrm{NS}, \mathrm{p}<0.05)$.

The LV mass regression indexes vary significantly in the both groups. iLVMR were $21.5(-30.8-117.3)$ for AS patients and 25.2 (11.6-82.21) for AR patients. To evaluate timing difference of LV mass regression the iLVMR in months was used. Last did not show significant changes between groups $(p=0.227)$. Although AR group showed increased iLVMR and iLVMR in months compare to AS group, these findings did not reach statistical significance. Moreover, there were no correlations between iLVMR and ILVMR in months to the MF (Figure 2).

$\mathrm{AH}$ - arterial hypertension; BAV - bicuspid aortic valve. BMI - body mass index; BSA - body surface area; DM - diabetes mellitus; IHD - ischemic heart disease; MI myocardial infarction; NS - non-significant; NYHA - New York Heart Association

\section{Table 3}

Left ventricular remodeling

\begin{tabular}{|l|l|l|l|l|l|l|}
\hline \multirow{2}{*}{ LV assessment } & \multicolumn{2}{l|}{ AS } & P-value & AR & P-value \\
\cline { 2 - 7 } & $\begin{array}{l}\text { Pre-AVR } \\
(\mathrm{n}=116)\end{array}$ & $\begin{array}{l}\text { Post-AVR } \\
(\mathrm{n}=86)\end{array}$ & & $\begin{array}{l}\text { Pre-AVR } \\
(\mathrm{n}=14)\end{array}$ & $\begin{array}{l}\text { Post-AVR } \\
(\mathrm{n}=11)\end{array}$ \\
\hline LVEDD (mm) & $50.1 \pm 8.5$ & $47.2 \pm 7.6$ & 0.05 & $56.3 \pm 3.7$ & $48.4 \pm 9.3$ & 0.05 \\
\hline iLVEDD (mm/m2) & $26.1 \pm 3.9$ & $24.1 \pm 3.8$ & 0.001 & $25.6 \pm 3.2$ & $23.4 \pm 5.2$ & 0.05 \\
\hline LV septal thickness (mm) & $14.4 \pm 4.3$ & $12.6 \pm 1.9$ & 0.001 & $12.5 \pm 2.3$ & $11.9 \pm 2.1$ & NS \\
\hline Posterior wall thickness (mm) & $12.3 \pm 1.7$ & $11.8 \pm 1.5$ & NS & $11.2 \pm 1.4$ & $11.9 \pm 2.3$ & NS \\
\hline LV mass (g) & $269.8 \pm 63.1$ & $222.8 \pm 58.4$ & 0.001 & $283.3 \pm 71.1$ & $216.5 \pm 74.8$ & 0.05 \\
\hline iLV mass (g/m2) & $139.1 \pm 29.9$ & $112.1 \pm 25.6$ & 0.001 & $136.6 \pm 26.7$ & $102.8 \pm 33.2$ & 0.001 \\
\hline LVH (\%) & $79(68.1 \%)$ & $44(51.2 \%)$ & 0.001 & $11(78.6 \%)$ & $4(36.4 \%)$ & 0.05 \\
\hline LV EF (\%) & $49.1 \pm 10.2$ & $48.9 \pm 7.4$ & NS & $40.6 \pm 8.3$ & $41.8 \pm 10.5$ & 0.05 \\
\hline Low EF (\%) & $15(12.9 \%)$ & $17(19.7 \%)$ & NS & No & $4(36.4 \%)$ & NS \\
\hline
\end{tabular}

iLVEDD - indexed left ventricular end-diastolic diameter; iLV mass - indexed left ventricular mass; LVEDD - left ventricular end-diastolic diameter; LV EF - left ventricular ejection fraction; LVH - left ventricular hypertrophy; LV mass - left ventricular mass. 


\begin{tabular}{llll}
\hline Variables & AS (n=116) & AR (n=14) & P-value \\
\hline MF (\%) & $6.5(0-52.8)$ & $4.9(0.5-23.6)$ & NS \\
mild & $108(93.1 \%)$ & $12(85.7 \%)$ & NS \\
moderate & $7(6.0 \%)$ & $2(14.3 \%)$ & NS \\
severe & $1(0.9 \%)$ & No & NS \\
Procedural details & & & \\
Prosthesis size (mm) & $24.7 \pm 1.8$ & $26.0 \pm 1.8$ & 0.05 \\
Bioprosthesis & $94(81 \%)$ & $10(71.4 \%)$ & NS \\
PPM (\%) & $7(6.0 \%)$ & No & NS \\
CPB time (min) & $111.3 \pm 41.5$ & $109.0 \pm 33.1$ & NS \\
Cross-clamp time (min) & $70.1 \pm 25.1$ & $69.6 \pm 10.9$ & NS \\
Operation time (min) & $213.9 \pm 68.3$ & $215.7 \pm 46.8$ & NS \\
ICU stay (day) & $4.0(1-35)$ & $5.0(2-48)$ & 0.05 \\
Postoperative stay (day) & $12.0(1-129)$ & $14.0(8-64)$ & NS \\
Follow-up time (month) & $6.8 \pm 2.1$ & $6.6 \pm 2.4$ & NS \\
Therapy in follow-up & & $12(85.7 \%)$ & NS \\
Beta-blockers (\%) & $96(82.8 \%)$ & $10(71.4 \%)$ & NS \\
ACE inhibitors or & $74(63.8 \%)$ & $10(71.4 \%)$ & NS \\
angiotensin receptor & & & NS \\
antagonists (\%) & $109(94 \%)$ & $10(71.4 \%)$ & NS \\
Diuretics (\%) & $9(7.8 \%)$ & $5(35.7 \%)$ & NS \\
Spironaloctone (\%) & $64(55.2 \%)$ & NS \\
Statins (\%) & $57(49.1 \%)$ & $4(28.6 \%)$ & NS \\
Aspirin (\%) & $30(25.9 \%)$ & $3(21.4 \%)$ & $14.3 \%)$ \\
Anticoagulants (\%) & & & \\
Mortality (\%) & & & \\
\hline
\end{tabular}

MF - myocardial fibrosis; CPB - cardiopulmonary bypass time; ICU - intensive care unit; ACE - angiotensin converting enzyme inhibitors; NS - non-significant.

Figure 2. - Left ventricular mass regression indexes after AVR

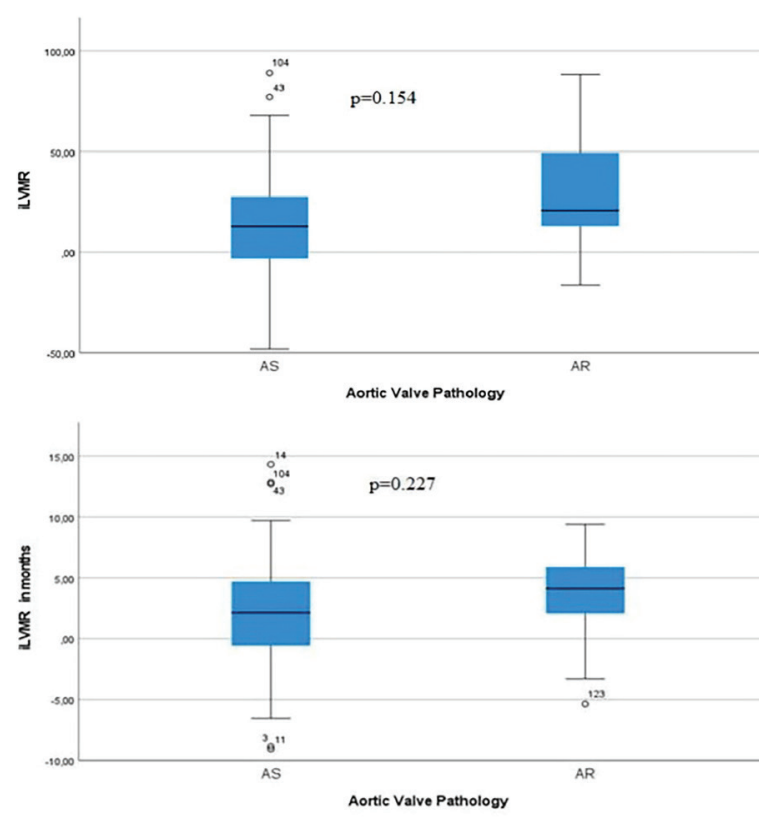

\section{Correlations between MF and LV parameters}

From the preoperative echocardiography data obtained in all 130 patients and in 97 patients' follow-up data, we investigated, whether MF and LV parameters were correlated. We did not found correlations between MF and LVM in preoperative, and

follow-up periods for AS and AR groups. Moreover, MF did not correlate significantly to iLVMR and iLVMR in months. A significant correlation exists in AS patients between MF and preoperative iLVEDD $(\mathrm{r}=0.21, \mathrm{p}=0.04)$.

\section{Discussion}

Aortic stenosis is the one of the predominant valve pathologies in the USA and Europe [11]. One fourth of symptomatic untreated AS will die in 2-3 years [12]. Moreover, it has been predicted that, in 30 years, the population older than 65 years old will increase at least twice [13]. AS is a fibrocalcific fusion of leaflets due to the progression of fibrosis and leaflet calcification $[14,15]$. Severe AS presents with blood flow obstruction and LV pressure afterload, which leads to LVH and subsequently results in heart failure. A similar mechanism probably develops in the coronary vessels of patients with atherosclerosis [16].

Aortic regurgitation (AR) has been detected in $2-5 \%$ of the population [17]. AR can be a consequence of the improper function of the aortic annulus, leaflets, or the aortic root. According to data from Framingham's study, 0.5\% AR requires a heart valve operation[17]. The primary pathology of the valve cusps and secondary pathology of the aortic root and annulus can be distinguished [18]. In addition, acute AR is characterized by a life-threatening high preload and afterload on normal LV, while chronic AR progresses over time and myocardium compensates for the regurgitation volume [19]. As a result, most of AR patients tend to develop eccentric hypertrophy with dilated LV [18].

LVH is a compensatory mechanism maintaining an adequate cardiac output in aortic stenosis and aortic regurgitation patients. In addition to functional adaptation, structural and molecular changes also appear [20]. LVH is known to be associated with a high morbimortality [21,22]. LVM regression dramatically decreases cardiovascular events caused by pressure overload in more than $50 \%$ of cases [23]. Recent evidence suggests that LVMR after AVR is an important survival predictor of degenerative aortic valve diseases [2426]. Maximal LV reduction appears in 6 months, whereas much slower progress has been seen in long follow-up periods [27]. In our study, we followed-up our groups in $6.77 \pm 2.05$ months. Despite the fact that LVMR after AVR appeared in both aortic stenosis and regurgitation cases [28], complete LVMR can be reached in a 2 and 5 year period, respectively. A similar trend was observed in our study, where the LVM of AS patients regressed better in the same follow-up time compared to AR patents. The preoperative LVM values of AS and AR groups were similar. Moreover, probably AS patients recovered faster compared to AR due to the less than $55 \mathrm{~mm}$ preoperative left ventricular enddiastolic dimension (LVEDD) and early stage of disease [29]. This may be one reason for the poor regression observed in the AR group in our study. Furthermore, the different myocardial response may be because of the relief of pressure overload in AS patients and combination of pressure and volume overload in AR patients [28].

$\mathrm{MF}$ is a result of a preventive response to cardiomyocytes death or injury from ventricular rupture [30]. In addition, AS and $\mathrm{SH}$, as examples of pressure overload, lead to interstitial and perivascular fibrosis. The severity of fibrosis is directly associated with the cardiac function and anticipated survival rate of AV disease patients [30,31]. In our study in the majority of our patients detected mild MF level. Similar results were reported by Podlesnikar et al. for AS and AR patients [32]. There has been interest in the MF level as an indicator of LVM changes after AVR. Several studies showed that the level of fibrosis affects 
the LV regression process [4,33]. Unfortunately, we could not compare mild, moderate and severe MF because of a small number of patients in moderate and severe MF groups.

$\mathrm{MF}$ is a result of eccentric or concentric LV hypertrophy due to volume (AR) or pressure (AS) overload [26]. You J. et al. stated that AS is characterized by myocardial fibrosis and apoptosis, whereas AR is mostly associated with angiogenesis [20]. Non-invasive measurement of MF showed a strong correlation with systolic and diastolic dysfunction in AS patients[34]. This is important in the case of early diagnosis by cardiovascular magnetic resonance (CMR) before a patient develops symptoms [32]. Similar data on diastolic function improvement in relation to diffuse fibrosis were presented by Treibel et al. 1 year post-AVR [4]. However, in our study, LVM in preoperative, early postoperative and follow-up periods did not correlate with the level of myocardial fibrosis. Moreover, iLVMR $\Delta$ and their monthly changes do not correlate with MF. Possible reason for that can be predominantly mild MF level in our study. Last can be explained by short waiting time before referring to the surgery.

A further research objective will include collagen I/III ratio assessment. It has been suggested, that shift towards collagen I associated with increased myocardial stiffness, whereas collagen III indicates reduced cardiac stiffness [35]. This can improve our knowledge on the time of surgery of patients with aortic valve diseases. Thus, probably, will help to predict better LVM regression after AVR.

\section{Study limitations}

The sample size was small and population is heterogeneous. Moreover, aortic regurgitation group relatively small and results should be treated with caution. Concomitant procedures and different type of prosthesis also can limit our study. Myocardial biopsy taken from localized part of heart, do not correspond with all myocardium. The short period of follow-up can influence on the results. Furthermore, we could not obtain detailed echocardiographic data of the deceased patients. Although angiotensin receptor blockers, beta-, and calcium channel blockers showed their effectiveness in LVMR after AVR [3640], this is the beyond the scope of present study.

\section{Conclusion}

The LVM reduction was observed in both AS and AR groups. LVM of AS group recovered more quickly than that of AR group. In our study MF does not affect LVM regression. Large cohort of patients with myocardial biopsies and longterm follow-up are needed to access the impact of the MF on the LVMR.

Disclosures: There is no conflict of interest for all authors.

Acknowledgements: All authors are members of the medical staff in the department and played a key role in the study.

\section{Funding: None.}

\section{References}

1. Gavina C, Falcão-Pires I, Pinho P, Manso MC, Gonçalves A, Rocha-Gonçalves F, et al. Relevance of residual left ventricular hypertrophy after surgery for isolated aortic stenosis. European Journal of Cardio-thoracic Surgery. 2016. CrossRef: https://doi.org/10.1093/ejcts/ ezv240. PubMed: https://www.ncbi.nlm.nih.gov/pubmed/?term=.

2. Azevedo CF, Nigri M, Higuchi ML, Pomerantzeff PM, Spina GS, Sampaio RO, et al. Prognostic significance of myocardial fibrosis quantification by histopathology and magnetic resonance imaging in patients with severe aortic valve disease. Journal of the American College of Cardiology. 2010; 56(4):278-287. CrossRef: https://doi.org/10.1016/j.jacc.2009.12.074. PubMed: https://www.ncbi.nlm. nih.gov/pubmed/?term $=$.

3. Schwartzkopff B, Frenzel H, Diekerhoff J, Betz P, Flasshove M, Schulte HD, et al. Morphometric investigation of human myocardium in arterial hypertension and valvular aortic stenosis. European Heart Journal. 1992. CrossRef: https://doi.org/10.1093/eurheartj/13. suppl_d.17. PubMed: https://www.ncbi.nlm.nih.gov/pubmed/?term=.

4. Treibel TA, Kozor R, Schofield R, Benedetti G, Fontana M, Bhuva AN, et al. Reverse Myocardial Remodeling Following Valve Replacement in Patients With Aortic Stenosis. Journal of the American College of Cardiology. 2018; 71(8):860-871. CrossRef: https://doi.org/10.1016/j.jacc.2017.12.035. PubMed: https://www.ncbi.nlm.nih.gov/pubmed/?term=.

5. Vassiliou VS, Perperoglou A, Raphael CE, Joshi S, Malley T, Everett R, et al. Midwall Fibrosis and 5-Year Outcome in Moderate and Severe Aortic Stenosis. Journal of the American College of Cardiology. 2017; 69(13):1755-1756. CrossRef: https://doi.org/10.1016/j. jacc.2017.01.034. PubMed: https://www.ncbi.nlm.nih.gov/pubmed/?term=.

6. Weidemann F, Herrmann S, Störk S, Niemann M, Frantz S, Lange V, et al. Impact of myocardial fibrosis in patients with symptomatic severe aortic stenosis. Circulation. 2009; 120(7):577-584. CrossRef: https://doi.org/10.1161/CIRCULATIONAHA.108.847772. PubMed: https://www.ncbi.nlm.nih.gov/pubmed/?term=.

7. Chang HW, Kim K-H, Kim JS, Kim K-H, Kim Y-J. Relationship between morphologic features of myocardial tissue and left ventricular function in patients with aortic valve disease and left ventricular hypertrophy. The Journal of heart valve disease. 2013; 22(4):476-483. eng. CrossRef: https://doi.org/. PubMed: https://www.ncbi.nlm.nih.gov/pubmed/?term=.

8. Lang RM, Badano LP, Mor-Avi V, Afilalo J, Armstrong A, Ernande L, et al. Recommendations for cardiac chamber quantification by echocardiography in adults: An update from the American society of echocardiography and the European association of cardiovascular imaging. European Heart Journal Cardiovascular Imaging. 2015. CrossRef: https://doi.org/10.1093/ehjci/jev014. PubMed: https:// www.ncbi.nlm.nih.gov/pubmed/?term=.

9. Pibarot P, Dumesnil JG. Hemodynamic and clinical impact of prosthesis-patient mismatch in the aortic valve position and its prevention. 2000 .

10. Tanaka M, Fujiwara H, Onodera T, Wu DJ, Hamashima Y, Kawai C. Quantitative analysis of myocardial fibrosis in normals, hypertensive hearts, and hypertrophic cardiomyopathy. Heart. 1986; 55(6):575-581. CrossRef: https://doi.org/10.1136/hrt.55.6.575. PubMed: https:// www.ncbi.nlm.nih.gov/pubmed/?term=.

11. !!! INVALID CITATION !!! [1, 2, 7]. CrossRef: https://doi.org/. PubMed: https://www.ncbi.nlm.nih.gov/pubmed/?term=. 
12. Bates ER. Treatment options in severe aortic stenosis. Circulation. 2011; 124(3):355-359. CrossRef: https://doi.org/10.1161/ CIRCULATIONAHA.110.974204. PubMed: https://www.ncbi.nlm.nih.gov/pubmed/?term=.

13. Chiappini B, Camurri N, Loforte A, Di Marco L, Di Bartolomeo R, Marinelli G. Outcome after aortic valve replacement in octogenarians. Annals of Thoracic Surgery. 2004. CrossRef: https://doi.org/10.1016/j.athoracsur.2003.12.060. PubMed: https://www.ncbi.nlm.nih. gov/pubmed/?term=.

14. Freeman RV, Otto CM. Spectrum of calcific aortic valve disease: Pathogenesis, disease progression, and treatment strategies. Circulation. 2005; 111(24):3316-3326. CrossRef: https://doi.org/10.1161/CIRCULATIONAHA.104.486738. PubMed: https://www.ncbi.nlm.nih. gov/pubmed/?term=.

15. Rajamannan NM, Bonow RO, Rahimtoola SH. Calcific aortic stenosis: An update. Nature Clinical Practice Cardiovascular Medicine. 2007; 4(5):254-262. CrossRef: https://doi.org/10.1038/ncpcardio0827. PubMed: https://www.ncbi.nlm.nih.gov/pubmed/?term=.

16. Stewart BF, Siscovick D, Lind BK, Gardin JM, Gottdiener JS, Smith VE, et al. Clinical factors associated with calcific aortic valve disease. Journal of the American College of Cardiology. 1997. CrossRef: https://doi.org/10.1016/S0735-1097(96)00563-3. PubMed: https://www.ncbi.nlm.nih.gov/pubmed/?term=.

17. Maurer G. Aortic regurgitation. 2006.

18. Supino PG, Borer JS, Preibisz J, Bornstein A. The Epidemiology of Valvular Heart Disease: a Growing Public Health Problem. 2006.

19. Flint N, Wunderlich NC, Shmueli H, Ben-Zekry S, Siegel RJ, Beigel R. Aortic Regurgitation. Current Cardiology Reports. 2019; 21(7). CrossRef: https://doi.org/10.1007/s11886-019-1144-6. PubMed: https://www.ncbi.nlm.nih.gov/pubmed/?term=.

20. You J, Wu J, Zhang Q, Ye Y, Wang S, Huang J, et al. Differential cardiac hypertrophy and signaling pathways in pressure versus volume overload. American Journal of Physiology - Heart and Circulatory Physiology. 2018; 314(3):H552-H562. CrossRef: https://doi. org/10.1152/ajpheart.00212.2017. PubMed: https://www.ncbi.nlm.nih.gov/pubmed/?term=.

21. Chuang ML, Gona P, Salton CJ, Yeon SB, Kissinger KV, Blease SJ, et al. Usefulness of the left ventricular myocardial contraction fraction in healthy men and women to predict cardiovascular morbidity and mortality. American Journal of Cardiology. 2012; 109(10):14541458. CrossRef: https://doi.org/10.1016/j.amjcard.2012.01.357. PubMed: https://www.ncbi.nlm.nih.gov/pubmed/?term=.

22. Capoulade R, Clavel MA, Mathieu P, Côté N, Dumesnil JG, Arsenault M, et al. Impact of hypertension and renin-angiotensin system inhibitors in aortic stenosis. European Journal of Clinical Investigation. 2013. CrossRef: https://doi.org/10.1111/eci.12169. PubMed: https://www.ncbi.nlm.nih.gov/pubmed/?term=.

23. Verdecchia P, Angeli F, Achilli P, Castellani C, Broccatelli A, Gattobigio R, et al. Echocardiographic left ventricular hypertrophy in hypertension: Marker for future events or mediator of events? Current Opinion in Cardiology. 2007; 22(4):329-334. CrossRef: https:// doi.org/10.1097/HCO.0b013e3280ebb413. PubMed: https://www.ncbi.nlm.nih.gov/pubmed/?term=.

24. Ali A, Patel A, Ali Z, Abu-Omar Y, Saeed A, Athanasiou T, et al. Enhanced left ventricular mass regression after aortic valve replacement in patients with aortic stenosis is associated with improved long-term survival. Journal of Thoracic and Cardiovascular Surgery. 2011; 142(2):285-291. CrossRef: https://doi.org/10.1016/j.jtcvs.2010.08.084. PubMed: https://www.ncbi.nlm.nih.gov/pubmed/?term=.

25. Lund O, Emmertsen K, Dørup I, Jensen FT, Flø C. Regression of left ventricular hypertrophy during 10 years after valve replacement for aortic stenosis is related to the preoperative risk profile. European Heart Journal. 2003; 24(15):1437-1446. CrossRef: https://doi. org/10.1016/S0195-668X(03)00316-6. PubMed: https://www.ncbi.nlm.nih.gov/pubmed/?term=.

26. Lamb HJ, Beyerbacht HP, Roos AD, Laarse AVD, Vliegen HW, Leujes F, et al. Left Ventricular Remodeling Early After Aortic Valve Replacement : Differential Effects on Diastolic Function in Aortic Valve Stenosis and Aortic Regurgitation. Journal of the American College of Cardiology. 2002; 40(12):2182-2188. CrossRef: https://doi.org/10.1016/S0735-1097(02)02604-9. PubMed: https://www. ncbi.nlm.nih.gov/pubmed/?term=.

27. Zhao Y. Effect of valve replacement for aortic stenosis on ventricular function2011.

28. Vollema EM, Singh GK, Prihadi EA, Regeer MV, Ewe SH, Ng ACT, et al. Time course of left ventricular remodelling and mechanics after aortic valve surgery : aortic stenosis vs . aortic regurgitation. 2020; 31(2019):1105-1111. CrossRef: https://doi.org/10.1093/ehjci/ jez049. PubMed: https://www.ncbi.nlm.nih.gov/pubmed/?term=.

29. Une D, Mesana L, Chan V, Maklin M, Chan R, Masters RG, et al. Clinical impact of changes in left ventricular function after aortic valve replacement: Analysis from 3112 patients. Circulation. 2015; 132(8):741-747. CrossRef: https://doi.org/10.1161/ CIRCULATIONAHA.115.015371. PubMed: https://www.ncbi.nlm.nih.gov/pubmed/?term=.

30. Frangogiannis NG. Cardiac fibrosis: Cell biological mechanisms, molecular pathways and therapeutic opportunities. Molecular Aspects of Medicine. 2019; 65(July 2018):70-99. CrossRef: https://doi.org/10.1016/j.mam.2018.07.001. PubMed: https://www.ncbi.nlm.nih. $\mathrm{gov} / \mathrm{pubmed} /$ term $=$.

31. Milano AD, Faggian G, Dodonov M, Golia G, Tomezzoli A, Bortolotti U, et al. Prognostic value of myocardial fibrosis in patients with severe aortic valve stenosis. Journal of Thoracic and Cardiovascular Surgery. 2012; 144(4):830-837. CrossRef: https://doi. org/10.1016/j.jtcvs.2011.11.024. PubMed: https:/www.ncbi.nlm.nih.gov/pubmed/?term=.

32. Podlesnikar T, Delgado V, Bax JJ. Cardiovascular magnetic resonance imaging to assess myocardial fibrosis in valvular heart disease. International Journal of Cardiovascular Imaging. 2018; 34(1):97-112. CrossRef: https://doi.org/10.1007/s10554-017-1195-y. PubMed: https://www.ncbi.nlm.nih.gov/pubmed/?term=.

33. Petrov G, Regitz-Zagrosek V, Lehmkuhl E, Krabatsch T, Dunkel A, Dandel M, et al. Regression of myocardial hypertrophy after aortic valve replacement: Faster in women? Circulation. 2010; 122(11 SUPPL. 1):23-28. CrossRef: https://doi.org/10.1161/ CIRCULATIONAHA.109.927764. PubMed: https://www.ncbi.nlm.nih.gov/pubmed/?term=.

34. Lee SP, Park SJ, Kim YJ, Chang SA, Park EA, Kim HK, et al. Early detection of subclinical ventricular deterioration in aortic stenosis with cardiovascular magnetic resonance and echocardiography. Journal of Cardiovascular Magnetic Resonance. 2013; $15(1): 1-1$. CrossRef: https://doi.org/10.1186/1532-429X-15-72. PubMed: https://www.ncbi.nlm.nih.gov/pubmed/?term=.

35. Díez J, Querejeta R, López B, González A, Larman M, Martínez Ubago JL. Losartan-dependent regression of myocardial fibrosis is associated with reduction of left ventricular chamber stiffness in hypertensive patients. Circulation. 2002. CrossRef: https://doi. org/10.1161/01.CIR.0000017264.66561.3D. PubMed: https://www.ncbi.nlm.nih.gov/pubmed/?term=. 
36. Dahl JS, Videbaek L, Poulsen MK, Pellikka PA, Veien K, Andersen LI, et al. Effect of candesartan treatment on left ventricular remodeling after aortic valve replacement for aortic stenosis. American Journal of Cardiology. 2010; 106(5):713-719. CrossRef: https://doi.org/10.1016/j.amjcard.2010.04.028. PubMed: https:/www.ncbi.nlm.nih.gov/pubmed/?term=.

37. Linhartová K, Filipovský J, Čerbák R, Šterbáková G, Hanišová I, Beránek V. Severe aortic stenosis and its association with hypertension: Analysis of clinical and echocardiographic parameters. Blood Pressure. 2007. CrossRef: https://doi.org/10.1080/08037050701343241. PubMed: https://www.ncbi.nlm.nih.gov/pubmed/?term=.

38. Helder MRK, Ugur M, Bavaria JE, Kshettry VR, Schaff HV. ACQUIRED CARDIOVASCULAR DISEASE : AORTIC VALVE The effect of postoperative medical treatment on left ventricular mass regression after aortic valve replacement. The Journal of Thoracic and Cardiovascular Surgery. 2015; 149(3):781-786. CrossRef: https://doi.org/10.1016/j.jtcvs.2014.10.034. PubMed: https://www. ncbi.nlm.nih.gov/pubmed/?term=.

39. Hall SA, Cigarroa CG, Marcoux L, Risser RC, Grayburn PA, Eichhorn EJ. Time course of improvement in left ventricular function, mass and geometry in patients with congestive heart failure treated with beta-adrenergic blockade. Journal of the American College of Cardiology. 1995. CrossRef: https://doi.org/10.1016/0735-1097(94)00543-Y. PubMed: https://www.ncbi.nlm.nih.gov/pubmed/?term=.

40. Reiken S, Wehrens XHT, Vest JA, Barbone A, Klotz S, Mancini D, et al. $\beta$-blockers restore calcium release channel function and improve cardiac muscle performance in human heart failure. Circulation. 2003. CrossRef: https://doi.org/10.1161/01.CIR.0000068316.53218.49. PubMed: https://www.ncbi.nlm.nih.gov/pubmed/?term=. 